\title{
Review
}

\section{Cellular Physiolosy

\section{The Role of Pendrin in the Development of the Murine Inner Ear}

\author{
Philine Wangemann
}

Anatomy \& Physiology Department, Kansas State University, Manhattan, Kansas

\section{Key Words}

Slc26a Enlarged vestibular aqueduct $\cdot$ Development

- Hearing • Cochlea - Endolymphatic sac • Genetic disease model

\begin{abstract}
Enlargement of the vestibular aqueduct (EVA) is a common inner ear malformation found in children with sensorineural hearing loss that is frequently associated with loss-of-function or hypo-function mutations of SLC26A4. SLC26A4 codes for pendrin, which is a protein that is expressed in apical membranes of selected epithelia and functions as an anion exchanger. The comparatively high prevalence of EVA provides a strong imperative to develop rational interventions that delay, ameliorate or prevent hearing loss associated with this phenotype. The development of rational interventions requires a fundamental understanding of the role that pendrin plays in the normal development of hearing, as well as a detailed understanding of the pathobiologic mechanisms that, in the absence of fully functional pendrin, lead to an unstable hearing phenotype, with fluctuating or progressive loss of hearing. This review summarizes studies in mouse models that have
\end{abstract}

\section{KARGER}

Fax +4161306 1234

E-Mail karger@karger.ch

www.karger.com
(C) 2011 S. Karger AG, Basel

$1015-8987 / 11 / 0283-0527 \$ 38.00 / 0$

Accessible online at: www.karger.com/cpb focused on delineating the role of pendrin in the physiology of the inner ear and the pathobiology that leads to hearing loss.

Copyright @ 2011 S. Karger AG, Basel

\section{Introduction}

Enlargement of the vestibular aqueduct (EVA) is a malformation that is commonly identified in children with sensorineural hearing loss $[1,2]$. In some populations, mutations of SLC26A4 (MIM \#605646) occur in as many as $13-14 \%$ of deaf subjects [3, 4]. Phenotypes include an enlarged vestibular aqueduct (EVA or DFNB4; MIM \#600791) and progressive, often fluctuating, hearing loss with an onset typically before or around the time of speech and language acquisition [5, 6]. Vestibular deficits may be present but symptoms and signs are far less prominent due to compensatory mechanisms $[7,8]$. The high prevalence of EVA-associated hearing loss provides an imperative to investigate the etiology of SLC26A4related deafness with the ultimate goal to develop strategies to preserve hearing in affected individuals. This review summarizes studies in mouse models that have focused on delineating the role of pendrin in the physiology

Philine Wangemann

Anatomy \& Physiology Department

Kansas State University, 205 Coles Hall

Manhattan, Kansas 66506 (USA)

Tel. +1 785532 4863, Fax +1 785532 4557, E-Mail wange@vet.ksu.edu 
of hearing. Clinical phenotypes and the genetics of hearing loss associated with EVA are reviewed elsewhere [9, $10]$.

\section{Development of the murine inner ear}

The development of the murine inner ear begins with an ectodermal invagination that forms an otocyst at embryonic day (E) 9.5 (Fig. 1; for a recent review, see [11]). The otocyst is initially filled with amniotic fluid of plasma-like composition [12]. When and how the developing epithelia change the composition of the luminal fluid is currently unknown. Between E10 and E10.5, two protrusions begin to extend from the otocyst; one forms the cochlea and the other forms the endolymphatic sac. While the protrusions elongate and the cochlea coils, the center of the otocyst reorganizes into the vestibular labyrinth. The lumen of the endolymphatic sac opens at E10.5 and the lumen of the cochlear protrusion opens at E14.5 [13]. Lumen formation depends on fluid secretion in the vestibular labyrinth and fluid absorption in the endolymphatic sac [13]. Fluid secretion is most likely driven by ion transport; however, which ions are transported to promote lumen formation during embryonic development is currently unknown. This is in contrast to the well-defined composition of mature endolymph that is widely believed to arise after P3 $[14,15]$.

The mature inner ear consists of two arrays of interconnected fluid compartments that are enclosed by highly heterogeneous epithelia (Fig. 1). One array includes the cochlea, the saccule and the endolymphatic duct and sac. The other array includes the utricle, three ampullae and three semicircular canals [16]. The luminal fluid enclosed in both arrays of epithelia-lined compartments is called endolymph and the fluid surrounding the epithelium is called perilymph. Endolymph is an unusual extracellular fluid in that it contains in most parts of the mature inner ear, with the notable exception of the endolymphatic sac, a high $\mathrm{K}^{+}$ concentration and low $\mathrm{Na}^{+}$and $\mathrm{Ca}^{2+}$ concentrations. The composition of perilymph, in contrast, is more like a conventional extracellular fluid that contains $\mathrm{Na}^{+}$, $\mathrm{K}^{+}$and $\mathrm{Ca}^{2+}$ concentrations similar to other extracellular fluids, such as plasma or cerebrospinal fluid. For tables that list fluid compositions of adult inner ears, see [14].

Stimulation of the inner ear sensory organs is derived from the appropriate mechanical stimulus, which is sound for the cochlea and angular and linear acceleration, including gravity, for the vestibular labyrinth.
The transduction channels located in the hair bundles of the vestibular sensory cells acquire mechanosensitivity at E17 [17, 18]. The onset of vestibular function, however, is $\sim 8$ days later, at $\sim \mathrm{P} 4$, concurrent with the general maturation of the organ and the maturation of the innervation $[19,20]$. Similarly, transduction channels in cochlear hair cells acquire mature mechanosensitivity at $\mathrm{P} 0$ [18], and onset of hearing is $\sim 12$ days later, at P12, concurrent with the general maturation of the cochlea and the maturation of the endocochlear potential, which rises between P6 and P15 [21-23].

\section{Onset and location of pendrin expression in the murine inner ear}

Pendrin is expressed in epithelial cells in the cochlea, the vestibular labyrinth and in the endolymphatic sac of the inner ear [24, 25] (Fig. 2). In the endolymphatic sac, pendrin is expressed in mitochondrial-rich cells that are interspersed among the principal ribosomal-rich cells [25-27]. In the cochlea, pendrin is expressed in a spiraling sheet of outer sulcus and spindle cells located in the lateral wall while in the vestibular labyrinth, pendrin is expressed in sheets of transitional cells that surround sensory cell patches that are engaged in cation reabsorption [25, 28, 29].

The earliest expression of pendrin in the inner ear occurs in the endolymphatic sac at embryonic day (E) 11.5 and surges steeply from E13.5 to E14.5 [30] (Fig. 3). The onset of expression in the cochlea, utricle and saccule occurs at E13.5-E14.5 and the onset of expression in ampullae occur at E16.5.

\section{Pendrin is a $\mathrm{Cl}^{-} / \mathrm{HCO}_{3}^{-}$exchanger in the inner ear}

Pendrin in the inner ear functions mainly as a $\mathrm{Cl}^{-} /$ $\mathrm{HCO}_{3}^{-}$exchanger $[23,30,31]$. Functionality was tested in spiral prominence epithelial cells using a microfluorometric assay that utilizes specific characteristics of pendrin including sensitivity to DIDS, transport of alkaline equivalents $\mathrm{OH}^{-}$and $\mathrm{HCO}_{3}$ and the fact that pendrin, unlike other anion exchangers, transports formate [23]. Consistent with pendrin-mediated transport of $\mathrm{HCO}_{3}{ }^{-}$into endolymph are the findings that mice lacking pendrin have a more acidic endolymph in the cochlea, the utricle and the endolymphatic sac $[23$, $30,31]$. 
Fig. 1. Development of the murine inner ear. Inner ear development begins with an ectodermal invagination at embryonic (E) day 9 and the formation of an otic vesicle at E9.5. The endolymphatic sac and the cochlea develop as protrusions of the otic vesicle at E10 and E11, respectively. The lumen of the endolymphatic sac and the cochlea open at E11 and E14.5, respectively. Two complete turns of the cochlea and a complete vestibular labyrinth consisting of the saccule, utricle, ampullae, endolymphatic duct (ED), and endolymphatic sac (ES) are formed by E18. Schematics were created by author and inspired by published photomicrographs $[16,52]$. A similar diagram of the cochlea at E18 has been contributed by the author to another publication [13].

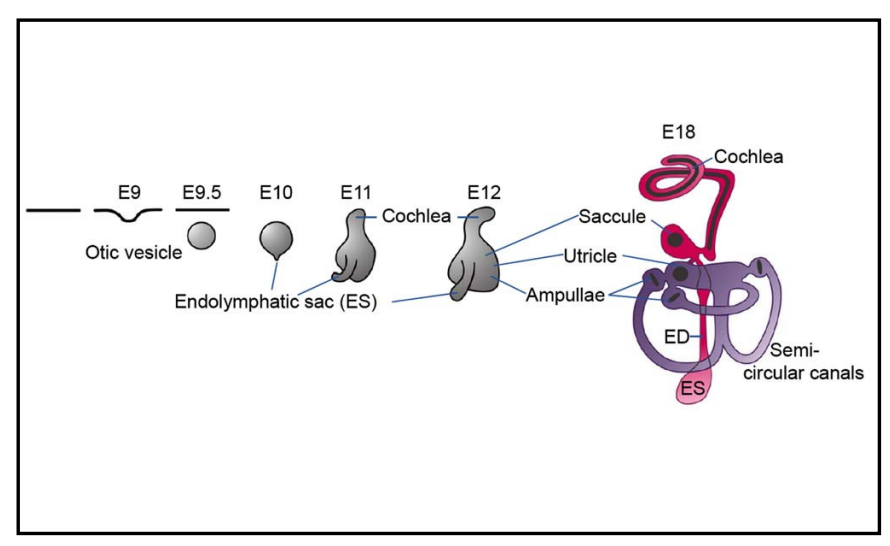

Fig. 2. Location of pendrin expression in the murine inner ear. The endolymphatic duct and sac, the cochlea, the utricle and saccule, and the ampullae contain epithelialined luminal compartments that are filled with endolymph and surrounded by perilymph, with the exception of the endolymphatic sac, which is surrounded by cerebrospinal fluid. A) Cross-sections of the endolymphatic duct and sac. The depicted simple morphology of the endolymphatic sac (ES) represents the late phase of embryonic development. During the early postnatal period of development,

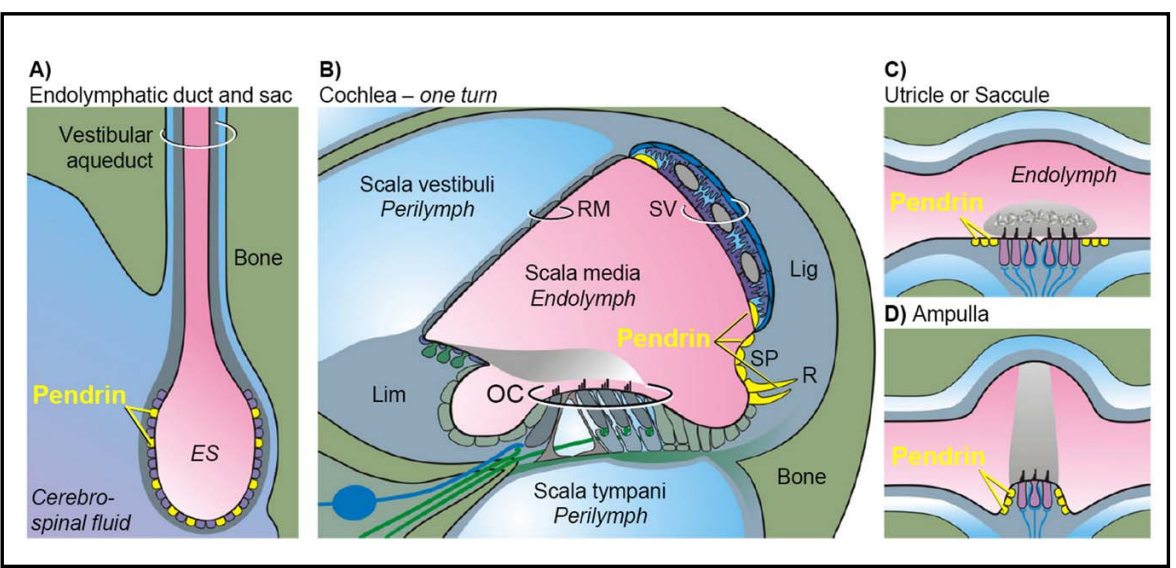
the morphology of the endolymphatic sac becomes more complex with epithelial ridges and tubular infoldings. Throughout life, however, the endolymphatic duct penetrates through a canal in the bone, which is the vestibular aqueduct. Pendrin is most prominently expressed in the apical membrane of mitochondria-rich cells in the endolymphatic sac. B) Cross-section of one turn of the cochlea. The depicted morphology of the cochlea represents the mature stage of development which is acquired during the second postnatal week. The cochlea consists of an epithelia-lined duct that is filled with endolymph. This duct is surrounded by two open fluid compartments that are filled with perilymph. The main structures of the cochlear duct are the stria vascularis (SV), Reissner's membrane (RM) and the organ of Corti (OC). Stria vascularis generates the endocochlear potential and secretes $\mathrm{K}^{+}$ into endolymph. The organ of Corti contains the sensory hair cells. Pendrin is expressed in epithelial cells of the spiral prominence (SP), in root cells (R) and in spindle cells of stria vascularis. Other relevant structures include the spiral limbus (Lim) and the spiral ligament (Lig). C-D) Cross-sections of the saccule or utricle and an ampulla. Pendrin is expressed in transitional cells, which are epithelial cells surrounding the sensory hair-cell patches in the saccule, utricle and ampulla and that are engaged in cation absorption. Schematic diagrams created by the author. A similar diagram was contributed by the author to another paper [53].

\section{Pendrin expression is essential for the development of a hearing phenotype in mice}

Work towards an understanding of the role of pendrin in hearing has been tremendously accelerated by

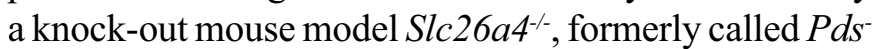
1- that lacks exon 8 of Slc26a4 [32]. Studies in these mice demonstrate that pendrin is essential for the development of a normal and robust hearing phenotype.

Pendrin in Inner Ear Development
Slc26a4 $4^{-/}$mice fail to develop a normal hearing phenotype,

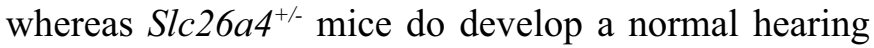
phenotype. Slc26a4 $4^{-/}$mice have been used to delineate primary and secondary consequences of a lack of pendrin expression on the development of the inner ear, hearing and balance [13, 23, 25, 30, 31, 33-36]. More recently two additional mouse models have been established; one is based on a missense mutation of Slc26a4 [37] and the other is a knock-in of a splice-site mutation at exon 8 of Slc26a4 [38]. 
Fig. 3. Time course of development between embryonic day 9.5 and postnatal day 15 in the presence and absence of pendrin. Key events in the development of the cochlea are noted above the time line and key events in the development of the endolymphatic sac are noted below the time line. Events that take place in the absence of functional pendrin expression are depicted in red font. Abbreviations are: ES, endolymphatic sac; Cx26, connexin 26; SV, stria vascularis; OC, organ of Corti; EP, endocochlear potential; $\mathrm{OHC}$, outer hair cells.

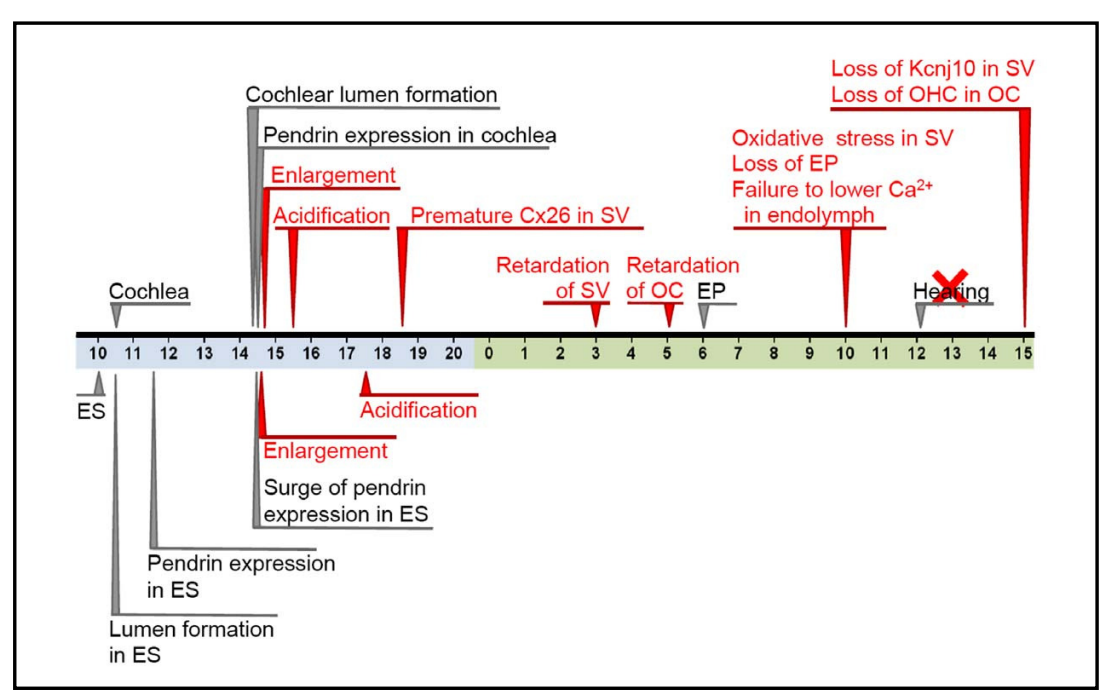

Fig. 4. Cochlear enlargement is key event in the pathobiology leading to the failure to acquire a normal hearing phenotype. A) Diagram illustrating that development of the inner ear, including cochlear lumen formation, depends on fluid secretion in the vestibular labyrinth and fluid absorption in the endolymphatic sac. A similar

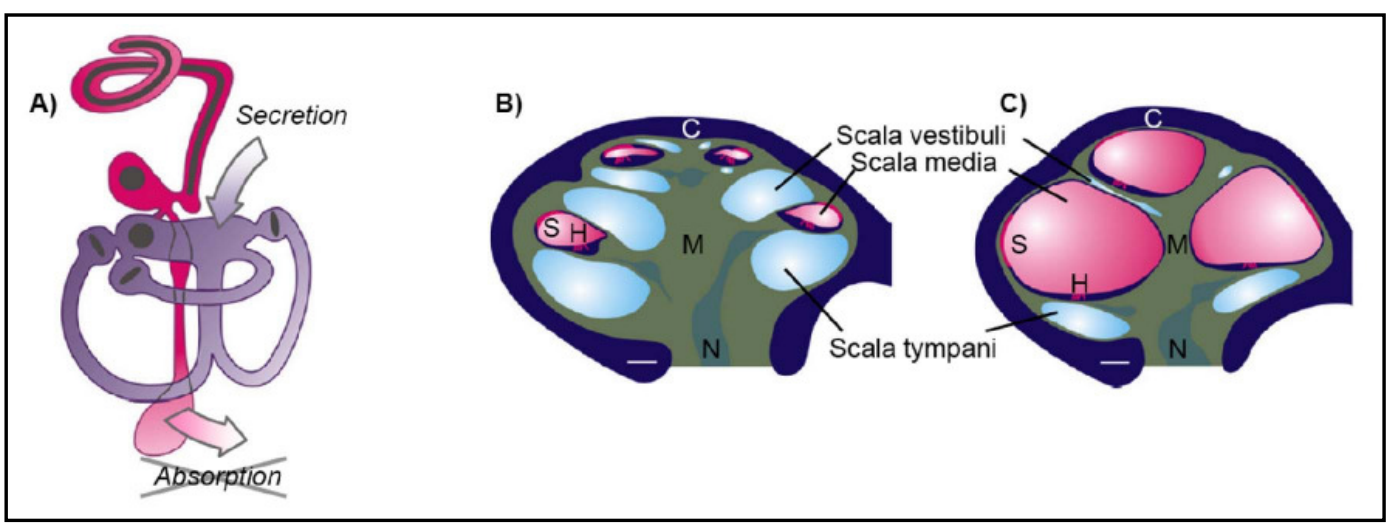
diagram has been contributed by the author to another publication [13]. B-C) Loss of functional pendrin expression leads to a 10-

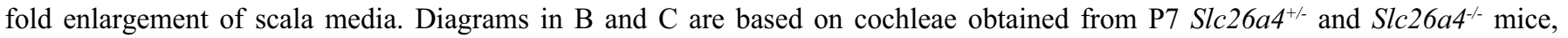
respectively [9]. Abbreviations: S, stria vascularis; H, hair cells in the organ of Corti; M, modiolus; and N, cochlear nerve including spiral ganglion.

\section{Primary consequences of a lack of pendrin expression: Enlargement and acidification}

The first pathobiological alteration in Slc26a4 $4^{-/}$mice is an enlargement of the entire membranous labyrinth that begins at E14.5 and is most dramatic in the endolymphatic sac but also present at this early time in the cochlea [30, 32]. The enlargement depends on a balance between fluid secretion in the vestibular labyrinth that 'pumps up' the cochlea and fluid absorption in the endolymphatic sac that 'drains' the cochlea [13] (Fig. 4). Neither the mechanisms of fluid secretion nor the mechanisms of fluid absorption are understood in the in the embryonic inner ear. Lumen formation and enlargement are most likely dependent on passive water movements osmotically driven by ion transport. The enlargement causes stretching of epithelial cells with the notable exception of vestibular and cochlear sensory cells that may be protected by dense actin rings associated with rigid tight junctions that provide greater structural stability. By E18.5 the enlargement amounts to a $\sim 10$ fold larger volume of scala media in Slc26a4 ${ }^{-/}$ mice compared to Slc26a4 $4^{+/}$mice (Fig. 4). The onset of this enlargement, however, coincides with cochlear lumen formation at E14.5 [30].

The second pathobiological alteration in the inner ear of Slc26a4 $4^{--}$mice is an acidification of cochlear endolymph that develops at E15.5, which is 1-2 days after the failed onset of pendrin expression in the cochlea [30] (Fig. 3). Lack of pendrin expression also causes an acidification of the endolymphatic sac, although later, at E17.5, which may be due to greater buffering power in the endolymphatic sac [30]. The acidification of endolymph is not limited to the embryonic endolymphatic sac and cochlea but has been demonstrated in the adult cochlea and in the utricle of the vestibular labyrinth of Slc26a4 $4^{--}$mice $[23,31]$.

These two primary pathobiological alterations, the enlargement and the luminal acidification, are of greatest 
significance because they spread the effect of pendrin deficiency from pendrin-expressing cells to a multitude of other cells [13]. The acidification affects all $\mathrm{pH}-$ sensitive mechanisms and the enlargement may impair cell-to-cell communication due to lengthening of diffusional distances between epithelial cells and between epithelial cells and mesenchymal cells.

\section{Secondary consequence of a lack of pendrin expression: Impaired cell-to-cell communication}

Impaired cell-to-cell communication may be responsible for the premature onset of connexin 26 expression that has been observed in basal cells of stria vascularis at E18.5 and for the retarded development of stria vascularis that is most prominent at $\mathrm{P} 3$ [30] (Fig. 3). Further, impaired cell-to-cell communication may be responsible for the retarded development of the organ of Corti that is most prominent between P5 and P10 [36]. Cell stretching increases the diffusional distances between the cells located in the organ of Corti that bear thyroid hormone receptors and mesenchymal cells in the spiral limbus and spiral ligament that express deiodinase Dio2 between P6-8. Deiodinase type 2 is the enzyme that generates bioactive thyroid hormone tri-iodo-thyronine (T3) from the blood-borne prohormone thyroxine (T4) [39]. Delivery of T3 may depend on cell-to-cell diffusion via gap junctions and on the overall distance between the locations of hormone production and hormone receptors. Lengthening of these diffusional distances in Slc26a4 mice appears to be responsible for a local hypothyroidism that is evident from a delayed opening of the tunnel, a delayed arrival of efferent innervation, and delayed changes in gene expression levels [36]. It remains to be determined whether the retardation of stria vascularis leads to a delay in the onset of $\mathrm{K}^{+}$secretion, which is a major function of stria vascularis.

\section{Secondary consequence of a lack of pendrin expression: Oxidative stress, loss of Kcnj10 expression and loss of the endocochlear potential}

At P10, which is $\sim 2$ days prior to the normal onset of hearing in mice, the stria vascularis of Slc26a4 $4^{-/}$mice is subjected to oxidative stress [34] and fails to build up a normal endocochlear potential [23] (Fig. 3). Oxidative

Pendrin in Inner Ear Development stress results in elevated amounts of nitrated and oxidized proteins. Elevated amounts of oxidized and nitrated proteins were found in the stria vascularis but not in the adjacent spiral ligament of Slc26a4 ${ }^{-/}$mice [34]. The combination of oxidative and nitrative stress leads to a loss of the $\mathrm{K}^{+}$channel $\mathrm{Kcnj} 10$ that is responsible for the generation of the endocochlear potential $[34,40]$. Whether the integrity of tight junctions is weakened by cell stretching and/or acidification and whether this conceivable compromise contributes to the failure to build up a normal endocochlear potential is currently unknown. The impression that Slc26a4 ${ }^{-1}$ mice bear holes in the basal cell barrier, however, was later revealed to be an artifact caused by pigmentation that blocked the confocal laser beam $[25,27]$.

The endocochlear potential is essentially a $\mathrm{K}^{+}$ equilibrium potential generated by the $\mathrm{K}^{+}$channel $\mathrm{Kcnj} 10$ that is expressed in intermediate cells of the stria vascularis. The potential is generated across the basal cell barrier in conjunction with the very low $\mathrm{K}^{+}$ concentration of intrastrial fluid and the high $\mathrm{K}^{+}$ concentration in the cytosol of intermediate cells $[40,41]$. Marginal cells maintain the very low $\mathrm{K}^{+}$concentration of intrastrial fluid by transporting $\mathrm{K}^{+}$into endolymph. Suited for high rates of $\mathrm{K}^{+}$secretion, marginal cells are endowed with a high density of mitochondria and situated adjacent to capillaries. Sources of oxidative stress in stria vascularis include superoxide free radicals generated as a by-product of the mitochondrial metabolism and nitric oxide free radicals produced by nitric oxide synthase expressed in endothelial cells [34]. It is unclear whether oxidative stress in the stria vascularis of Slc26a $4^{-/}$mice is due to a failure to express sufficient levels of defense mechanisms or due to higher metabolic rates.

Elevated metabolic rates may be a function of higher rates of $\mathrm{K}^{+}$secretion necessary to maintain a normal endolymphatic $\mathrm{K}^{+}$concentration in an $\sim 10$-fold expanded volume of endolymph [27]. The enlarged volume may be prone to higher rates of $\mathrm{K}^{+}$leakage, which would need to be offset by higher rates of $\mathrm{K}^{+}$secretion. Marginal cells detect $\mathrm{K}^{+}$concentrations at the apical membrane by an unknown mechanism $[42,43]$. Low apical $\mathrm{K}^{+}$ concentrations lead to a marked increase in the rate of $\mathrm{K}^{+}$secretion. In addition, the $\mathrm{K}^{+}$channel Kcnq1, which mediates $\mathrm{K}^{+}$secretion across the apical membrane of marginal cells, is activated by extracellular acidification [44], which further increases the rate of $\mathrm{K}^{+}$secretion and metabolism, as well as oxidative and nitrative stress.

The endocochlear potential and oxidative/nitrative stress may comprise a negative feedback system that 
Fig. 5. Diagram of stria vascularis illustrating a negative feedback mechanism that leads to the fluctuating loss of $\mathrm{Kcnj} 10$, the $\mathrm{K}^{+}$channel that generates the endocochlear potential. Fluctuating losses of the endocochlear potential can be expected to lead to fluctuating losses of hearing. A similar diagram was contributed by the author to another paper [9].

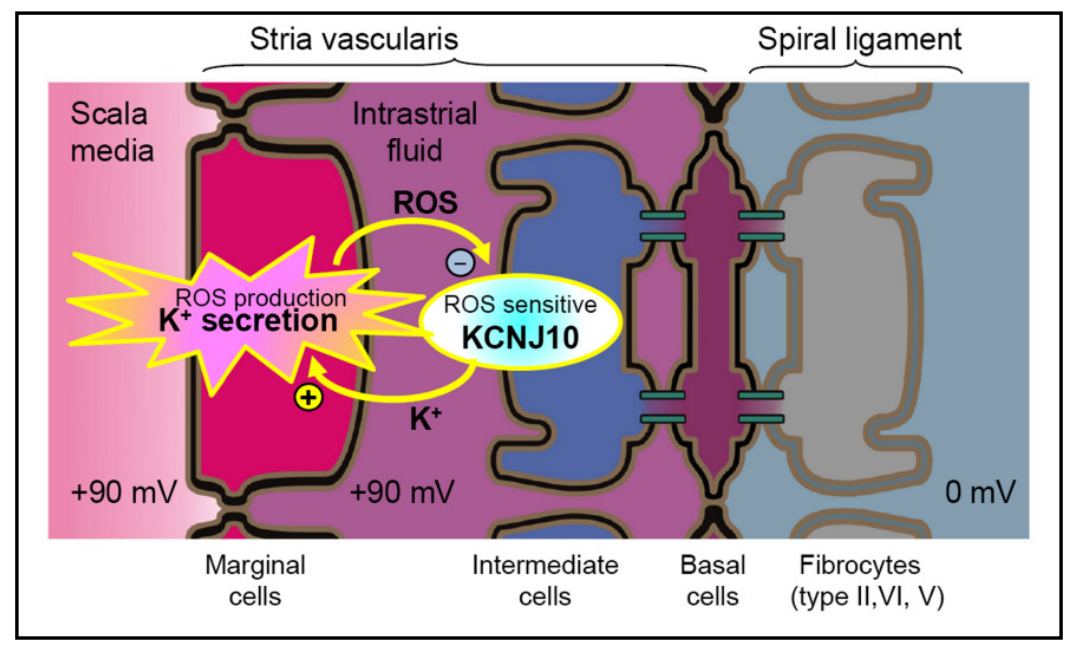

can oscillate and generate fluctuations in the endocochlear potential and in hearing threshold [13] (Fig. 5). It is conceivable that the sensitivity of the endocochlear potential to oxidative/nitrative stress is responsible for the fluctuating hearing loss documented in patients $[5,45-$ 47]. The hypothesized feedback loop is comprised of three elements. First, reactive oxygen species (ROS) including superoxide anion and nitric oxide are generated by marginal cells of stria vascularis as a byproduct of metabolism [34]. Second, the ROS-sensitive $\mathrm{K}^{+}$channel Kcnj10 that generates the endocochlear potential and supplies $\mathrm{K}^{+}$to the marginal cells $[41,43]$. Third, $\mathrm{K}^{+}$induced stimulation of $\mathrm{K}^{+}$secretion $[42,43]$. ROS-induced loss of Kcnj10 would abolish the endocochlear potential and hearing and the associated reduction in $\mathrm{K}^{+}$flux toward marginal cells would limit the rate of $\mathrm{K}^{+}$secretion, metabolism and ROS production. The reduced ROS production would then permit restoration of Kcnj10 expression, Kcnj10 channel function would restore the endocochlear potential and restore hearing but also supply increased amounts of $\mathrm{K}^{+}$to marginal cells, which again would stimulate $\mathrm{K}^{+}$secretion, metabolism and ROS production. Fluctuating hearing loss is hypothesized to be generated through such a feedback loop.

Secondary consequence of a lack of pendrin expression: Elevated endolymphatic $\mathrm{Ca}^{2+}$ concentrations and degeneration of sensory cells and stria vascularis

At $\mathrm{P} 10, \sim 2$ days prior to the normal onset of hearing, the cochlea fails to lower the endolymphatic $\mathrm{Ca}^{2+}$ to normal adult levels of $20 \mu \mathrm{M}$ [23] (Fig. 3). The failure to lower the endolymphatic $\mathrm{Ca}^{2+}$ concentration may be due to a lack of $\mathrm{Ca}^{2+}$ absorption via acid-sensitive epithelial $\mathrm{Ca}^{2+}$ channels [23, 31, 48]. Whether and how loss of pendrin leads to a loss of expression of $\mathrm{Ca}^{2+}$ transporters, as observed in the kidney [49], remains to be determined.

Sensory hair cells degenerate between P15 and P30 after a period of thyroid hormone deprivation and under the burden of an elevated luminal $\mathrm{Ca}^{2+}$ concentration, luminal acidification and the lack of an endocochlear potential [32]. Similarly, marginal cells of stria vascularis degenerate after P15 and macrophage invade stria vascularis at $\sim \mathrm{P} 30$ [33]. Curiously, the invasion of stria vascularis with pigmented macrophages is so dramatic that the structure acquires a dark appearance that is visible to the naked eye in isolated murine temporal bones [25].

\section{Location of essential pendrin expression}

The observation that pendrin is expressed in multiple locations within the inner ear raises the question whether all sites of pendrin expression are of equal importance or whether pendrin in some locations is of greater importance for the development of a normal hearing phenotype. A tentative answer toward this question can be deduced from observations made in Foxi $1^{-/}$mice [50, 51]. Foxil controls pendrin expression in the endolymphatic sac but not in the cochlea or the vestibular labyrinth. Consequently, Foxi $1^{-/}$mice express pendrin in the cochlea and the vestibular labyrinth but not in the endolymphatic sac. The observation that Foxi $1^{-/}$mice are deaf suggests that pendrin expression in the endolymphatic sac is essential for the development of a normal hearing phenotype. This finding is surprising from the standpoint that the endolymphatic sac is the inner ear structure that is most remote from the cochlea. The observation, however, is less surprising when considering that Foxi $^{-/-}$mice develop an enlargement of the inner ear similar to the enlargement found in Slc26a4 $4^{-/}$mice. Whether Foxi $1^{-/-}$ mice also develop an acidification, is currently not known. Regardless, deafness may be a common consequence of the enlargement. 


\section{Conclusions}

Humans bearing loss-of-function or hypo-function mutations of SLC26A4 develop normal or near-normal hearing but typically lose hearing progressively during childhood, often after a period of fluctuating hearing loss. This apparently fundamental difference between humans and mice, which fail to ever acquire normal hearing thresholds, should not obscure studies in mouse models that have provided unprecedented insights into the mechanisms that may be responsible for hearing loss in human patients. It is most likely that mouse models will be instrumental in the development of interventions that secure for children, who are bearing mutations of $S L C 26 A 4$, a life-time of normal hearing.

\section{Acknowledgements}

The author thanks Dr. Andrew J. Griffith (Otolaryngology Branch, National Institute on Deafness and Other Communication Disorders, National Institutes of Health, Rockville, Maryland, USA) for critical review of this manuscript. The work was supported by Kansas State University CVM-SMILE and the Kansas City Area Life Science Institute.

\section{References}

$>1$

Valvassori GE, Clemis JD: The large vestibular aqueduct syndrome. Laryngoscope 1978;88:723-728.

72 Arcand P, Desrosiers M, Dube J, Abela A The large vestibular aqueduct syndrome and sensorineural hearing loss in the pediatric population. J Otolaryngol 1991;20:247-250.

-3 Yuan Y, You Y, Huang D, Cui J, Wang Y, Wang Q, Yu F, Kang D, Yuan H, Han D, Dai P: Comprehensive molecular etiology analysis of nonsyndromic hearing impairment from typical areas in China. J Transl Med 2009;7:79.

$\checkmark 4 \mathrm{Wu} \mathrm{CC}, \mathrm{Lu}$ YC, Chen PJ, Yeh PL, Su YN, Hwu WL, Hsu CJ: Phenotypic analyses and mutation screening of the SLC26A4 and FOXI1 genes in 101 Taiwanese families with bilateral nonsyndromic enlarged vestibular aqueduct (DFNB4) or Pendred syndrome. Audiol Neurootol 2010;15:57-66.

Choi BY, Stewart AK, Madeo AC, Pryor SP, Lenhard S, Kittles R, Eisenman D, Jeffrey KH, Niparko J, Thomsen J, Arnos KS, Nance WE, King KA, Zalewski CK, Brewer CC, Shawker T, Reynolds JC, Butman JA, Karniski LP, Alper SL, Griffith AJ: Hypo-Functional SLC26A4 variants associated with nonsyndromic hearing loss and enlargement of the vestibular aqueduct: Genotype-phenotype correlation or coincidental polymorphisms? Hum Mutat 2009;30:599-608

Pryor SP, Madeo AC, Reynolds JC, Sarlis NJ, Arnos KS, Nance WE, Yang Y, Zalewski CK, Brewer CC, Butman JA, Griffith AJ: SLC26A4/PDS genotypephenotype correlation in hearing loss with enlargement of the vestibular aqueduct (EVA): evidence that Pendred syndrome and non-syndromic EVA are distinct clinical and genetic entities. J Med Genet 2005;42:159-165.
Zhou G, Gopen Q: Characteristics of 15 vestibular evoked myogenic potentials in children with enlarged vestibular aqueduct. Laryngoscope 2011;121:220225

Sugiura M, Sato E, Nakashima T, Sugiura J, Furuhashi A, Yoshino T, Nakayama A, Mori N, Murakami H, Naganawa S: Longterm follow-up in patients with Pendred syndrome: vestibular, auditory and other phenotypes. Eur Arch Otorhinolaryngol 2005;262:737-743.

9 Griffith AJ, Wangemann P: Hearing loss $>18$ associated with enlargement of the vestibular aqueduct: Mechanistic insights from clinical phenotypes, genotypes, and mouse models. Hear Res 2011;in press.

10 Ito T, Choi BY, King KA, Zalewski CK, Muskett J, Chattaraj P, Shawker T, 19 Reynolds JC, Butman JA, Brewer CC, Wangemann P, Alper SL, Griffith AJ: SLC26A4 genotypes and phenotypes associated with enlargement of the vestibular aqueduct. Cell Physiol Biochem 2011; in press.

11 Mansour SL, Schoenwolf GC: Morphogenesis of the inner ear, in Kelley $>21$ MW, Wu D, Popper AN, Fay RR (eds): Springer Handbook of Auditory Research: Development of the inner ear. Springer New York, 2005, pp. 43-84.

12 Cheung CY, Brace RA: Amniotic fluid volume and composition in mouse pregnancy. J Soc Gynecol Investig 2005;12:558-562.

Kim HM, Wangemann P: Failure of fluid absorption in the endolymphatic sac initiates cochlear enlargement that leads to deafness in mice lacking pendrin expression. PLoS One 2010;5:e14041-. Wangemann P: Supporting sensory transduction: cochlear fluid homeostasis and the endocochlear potential. J Physiol 2006;576:11-21
Anniko M, Wroblewski R: Elemental composition of the developing inner ear. Ann Otol Rhinol Laryngol 1981;90:2532 .

16 Cantos R, Cole LK, Acampora D, Simeone A, Wu DK: Patterning of the mammalian cochlea. Proc Natl Acad Sci USA 2000;97:11707-11713.

17 Geleoc GS, Holt JR: Developmental acquisition of sensory transduction in hair cells of the mouse inner ear. Nat Neurosci 2003;6:1019-1020.

Lelli A, Asai Y, Forge A, Holt JR, Geleoc GS: Tonotopic gradient in the developmental acquisition of sensory transduction in outer hair cells of the mouse cochlea. J Neurophysiol 2009;101:2961-2973.

9 Nordemar H: Postnatal development of the vestibular sensory epithelium in the mouse. Acta Otolaryngol 1983;96:447456.

20 Desmadryl G, Sans A: Afferent innervation patterns in crista ampullaris of the mouse during ontogenesis. Brain Res Dev Brain Res 1990;52:183-189.

Steel KP, Barkway C: Another role for melanocytes: their importance for normal stria vascularis development in the mammalian inner ear. Development 1989;107:453-463.

22 Yamasaki M, Komune S, Shimozono M, Matsuda K, Haruta A: Development of monovalent ions in the endolymph in mouse cochlea. ORL J Otorhinolaryngol Relat Spec 2000;62:241-246.

23 Wangemann P, Nakaya K, Wu T, Maganti R, Itza EM, Sanneman J, Harbidge D, Billings S, Marcus DC: Loss of cochlear $\mathrm{HCO}_{3}^{-}$secretion causes deafness via endolymphatic acidification and inhibition of $\mathrm{Ca}^{2+}$ reabsorption in a Pendred syndrome mouse model. Am J Physiol Renal Physiol 2007;292:13451353. 
-24 Royaux IE, Wall SM, Karniski LP, Everett LA, Suzuki K, Knepper MA, Green ED: Pendrin, encoded by the Pendred syndrome gene, resides in the apical region of renal intercalated cells and mediates bicarbonate secretion. Proc Natl Acad Sci USA 2001;98:4221-4226.

-25 Wangemann P, Itza EM, Albrecht B, Wu T, Jabba SV, Maganti RJ, Lee JH, Everett LA, Wall SM, Royaux IE, Green ED, Marcus DC: Loss of KCNJ10 protein expression abolishes endocochlear potential and causes deafness in Pendred syndrome mouse model. BMC Medicine 2004;2:30.

26 Dou H, Xu J, Wang Z, Smith AN, Soleimani M, Karet FE, Greinwald JH, Jr., Choo D: Co-expression of pendrin, vacuolar $\mathrm{H}^{+}$-ATPase alpha4-subunit and carbonic anhydrase II in epithelial cells of the murine endolymphatic sac. J Histochem Cytochem 2004;52:13771384.

27 Royaux IE, Belyantseva IA, Wu T, Kachar B, Everett LA, Marcus DC, Green ED: Localization and functional studies of pendrin in the mouse inner ear provide insight about the etiology of deafness in pendred syndrome. J Assoc Res Otolaryngol 2003;4:394-404.

28 Lee JH, Chiba T, Marcus DC: P2X2 receptor mediates stimulation of parasensory cation absorption by cochlear outer sulcus cells and vestibular transitional cells. J Neurosci 39 2001;21:9168-9174.

29 Kim SH, Marcus DC: Regulation of sodium transport in the inner ear. Hear Res 2011;280:21-29.

$>30$ Kim HM, Wangemann P: Epithelial cell stretching and luminal acidification lead to a retarded development of stria vascularis and deafness in mice lacking pendrin. PLoS One 2011;6:e17949.

-31 Nakaya K, Harbidge DG, Wangemann P, Schultz BD, Green E, Wall SM, Marcus DC: Lack of pendrin HCO3- transport elevates vestibular endolymphatic $\left[\mathrm{Ca}^{2+}\right]$ by inhibition of acid-sensitive TRPV5 and TRPV6. Am J Physiol Renal Physiol 2007;292:1314-1321.

\32 Everett LA, Belyantseva IA, NobenTrauth K, Cantos R, Chen A, Thakkar SI, Hoogstraten-Miller SL, Kachar B, Wu DK, Green ED: Targeted disruption of mouse Pds provides insight about the inner-ear defects encountered in Pendred syndrome. Hum Mol Genet 2001;10:153161

-33 Jabba SV, Oelke A, Singh R, Maganti RJ, Feming S, Wall SM, Everett LA, Green ED, Wangemann P: Macrophage invasion contributes to degeneration of stria vascularis in Pendred syndrome mouse model. BMC Med 2006;4:37.
Singh R, Wangemann P: Free radical stress mediated loss of Kcnj10 protein expression in stria vascularis contributes to deafness in Pendred syndrome mouse model. Am J Physiol Renal Physiol 2008;294:F139-F148

35 Wangemann P, Jabba SV, Singh R, Wu T, Oelke A, Gollapudi ASB, Marcus DC: Deafness in Pendred Syndrome is related to free radical stress in stria vascularis. Proc Meniere's Meeting 2005;5:36-41. Wangemann P, Kim HM, Billings S, Nakaya K, Li X, Singh R, Sharlin DS, Forrest D, Marcus DC, Fong P: Developmental delays consistent with cochlear hypothyroidism contribute to failure to develop hearing in mice lacking Slc26a4/pendrin expression. Am J Physiol Renal Physiol 2009;297:F1435F1447

-37 Dror AA, Politi Y, Shahin H, Lenz DR, Dossena S, Nofziger C, Fuchs H, Hrabe dA, Paulmichl M, Weiner S, Avraham KB: Calcium oxalate stone formation in the inner ear as a result of an Slc26a4 mutation. J Biol Chem 2010;285:2172421735.

38 Lu YC, Wu CC, Shen WS, Yang TH, Yeh $\mathrm{TH}$, Chen PJ, Yu IS, Lin SW, Wong JM, Chang Q, Lin X, Hsu CJ: Establishment of a Knock-In Mouse Model with the SLC26A4 c.919-2A>G Mutation and Characterization of Its Pathology. PLoS One 2011;6:e22150.

Campos-Barros A, Amma LL, Faris JS, Shailam R, Kelley MW, Forrest D: Type 2 iodothyronine deiodinase expression in the cochlea before the onset of hearing. Proc Natl Acad Sci USA 2000;97:1287-1292.

40 Marcus DC, Wu T, Wangemann P, Kofuji P: KCNJ10 (Kir4.1) potassium channel knockout abolishes endocochlear potential. Am J Physiol Cell Physiol 2002;282:C403-C407.

41 Wangemann $\mathrm{P}: \mathrm{K}^{+}$cycling and the endocochlear potential. Hear Res 52 2002;165:1-9.

42 Wangemann P, Shen Z, Liu J: K ${ }^{+}$-induced stimulation of $\mathrm{K}^{+}$secretion involves activation of the $\mathrm{I}_{\mathrm{sK}}$ channel in vestibular dark cells. Hear Res 1996;100:201-210. Wangemann P, Liu J, Marcus DC: Ion transport mechanisms responsible for $\mathrm{K}^{+}$ secretion and the transepithelial voltage across marginal cells of stria vascularis in vitro. Hear Res 1995;84:19-29.

-44 Unsold B, Kerst G, Brousos H, Hubner M, Schreiber R, Nitschke R, Greger R, Bleich $\mathrm{M}$ : KCNE1 reverses the response of the human $\mathrm{K}^{+}$channel KCNQ1 to cytosolic $\mathrm{pH}$ changes and alters its pharmacology and sensitivity to temperature. Pflugers Arch 2000;441:368-378.
Suzuki H, Oshima A, Tsukamoto K, Abe S, Kumakawa K, Nagai K, Satoh H, Kanda Y, Iwasaki S, Usami S: Clinical characteristics and genotype-phenotype correlation of hearing loss patients with SLC26A4 mutations. Acta Otolaryngol 2007;127:1292-1297.

Cama E, Alemanno MS, Bellacchio E, Santarelli R, Carella M, Zelante L, Palladino T, Inches I, di Paola F, Arslan E, Melchionda S: Identification of a novel mutation in the SLC26A4 gene in an Italian with fluctuating sensorineural hearing loss. Int J Pediatr Otorhinolaryngol 2009;73:1458-1463.

$\checkmark 47$ Kitamura K, Takahashi K, Noguchi Y, Kuroishikawa Y, Tamagawa Y, Ishikawa $\mathrm{K}$, Ichimura K, Hagiwara H: Mutations of the Pendred syndrome gene (PDS) in patients with large vestibular aqueduct. Acta Otolaryngol 2000;120:137-141.

Yamauchi D, Nakaya K, Raveendran NN, Harbidge DG, Singh R, Wangemann P, Marcus DC: Expression of epithelial calcium transport system in rat cochlea and vestibular labyrinth. BMC Physiol 2010;10:1.

49 Barone S, Amlal H, Xu J, Soleimani M: Deletion of the $\mathrm{Cl}^{-} / \mathrm{HCO}_{3}^{-}$exchanger pendrin downregulates calcium-absorbing proteins in the kidney and causes calcium wasting. Nephrol Dial Transplant 2011; in press.

Hulander M, Kiernan AE, Blomqvist SR, Carlsson P, Samuelsson EJ, Johansson BR, Steel KP, Enerback S: Lack of pendrin expression leads to deafness and expansion of the endolymphatic compartment in inner ears of Foxil null mutant mice. Development 2003;130:2013-2025.

Hulander M, Wurst W, Carlsson P, Enerback S: The winged helix transcription factor Fkh10 is required for normal development of the inner ear. Nat Genet 1998;20:374-376.

Sajan SA, Warchol ME, Lovett M: Toward a systems biology of mouse inner ear organogenesis: gene expression pathways, patterns and network analysis. Genetics 2007;177:631-653.

53 Choi BY, Kim HM, Ito T, Lee KY, Li Z Monahan K, Wen Y, Wilson E, Kurima K, Saunder TL, Petralia RS, Wangemann P, Friedman TB, Griffith AJ: Mouse model of enlarged vestibular aqueducts defines temporal requirement of Slc26a4 expression for hearing acquisition. J Clin Invest 2011; in press. 